Proceedings of the 2010 Winter Simulation Conference

B. Johansson, S. Jain, J. Montoya-Torres, J. Hugan, and E. Yücesan, eds.

\title{
A SIMPLE AGENT-BASED SOCIAL IMPACT THEORY MODEL OF STUDENT STEM SELECTION
}

\author{
Theodore T. Allen \\ Nixon Davis \\ The Ohio State University \\ Department of Integrated Systems Engineering \\ 210 Baker Systems Bldg. - 1971 Neil Avenue \\ Columbus, $\mathrm{OH} 43210$
}

\begin{abstract}
There is a growing body of knowledge describing the economic and social challenge faced by the United States because of the small (14\%) and decreasing number of students pursuing Science, Technology, Engineering, and Mathematics (STEM) majors. We propose a simple two-period, agent-based simulation based on social impact theory to predict the \% yield of STEM majors. The model indicates that changes with minimal (if any) cost could more than double the STEM yield. For example, allocating the STEMoriented teaching talent in the first two years rather than in the last two years could increase yields by approximately $5.5 \%$. Also, dividing or segregating students based on STEM orientation could increase yield by over $10 \%$. We begin by briefly reviewing the literatures about STEM and social impact theory. Next, we describe our proposed model and numerical experiments using standard design of experiments methods. Finally, conclusions and suggestions for future research are provided.
\end{abstract}

\section{INTRODUCTION}

Agent-based modeling has been the focus of a large and growing body of research including contributions in computer science (e.g., see the Autonomous Agents and Multi-Agent Systems Journal), business and social science (e.g., see the Journal of Artificial Societies and Social Simulation), and operations research (Conte et al. 2001; Macal and North 2006; Huang et al. 2004; Carley 2006; Fang et al. 2002). For a recent review focusing on operations research, see Allen (2010) and for a fairly generic tutorial see Macal and North (2007). Macal and North (2007) suggest that modeling (in general) and agent based modeling (in particular) provides a fundamentally new, third way of carrying out social science research, in addition to argumentation and formalization.

This article focuses on modeling student decision-making related to selecting science, technology, engineering, and mathematics (STEM) related majors and careers. As we describe in Section 2, the challenge of current demographic trends relating to STEM for the United States economy is significant. These trends have alarmed many large U.S. based companies and triggered a major effort to study the phenomenon led by Raytheon scientists. These scientists and their collaborators have been involved in student surveys, obtaining demographic information, and system dynamics modeling effort of the STEM phenomenon, e.g., see Sanchez, Wells, and Attridge (2009).

The purpose of this research is to study the same STEM system with a relatively simple and transparent agent-based model. The model here is extended slightly from Nettle (1999) which was originally proposed to study linguistic pressures for conformity. Therefore, the focus here is more directly on the effects of peer pressure and biases from teachers and the environment. Possible drivers for the decline are 


\section{Allen and Davis}

investigated including the outsourcing of manufacturing work, i.e., worsening of the STEM-related job market, and the hiring of foreign-trained STEM workers, i.e., people with STEM-related interests not being present in the educational system to influence others.

Section 2 reviews selected literature describing the stem related challenges facing the United States. Section 3 describes some of the efforts to model STEM-related issues. Section 4 reviews social impact theory and describes the influence equation adopted in the model of education described in Section 5 . The model was implemented in NetLogo rather than, e.g., REPAST, because it seemed easier to create an interface for general users to be able to run simulations in NetLogo. Also, the library of existing applications in NetLogo seemed somewhat larger and learning curve was reported to be shorter. Section 6 describes a numerical study on the proposed model using design of experiments (DOE) methods and the potential implications for education policy makers. In Section 7, conclusions are provided along with opportunities for future research.

\section{THE CHALLENGE FOR THE UNITED STATES}

In recent years, there has been a dramatic decrease in the number of United States students pursuing careers in the area of STEM (e.g., see TAP 2008). Chen and Weko (2009) reported that in 1996 approximately $23 \%$ of post secondary students entered a STEM field and that in 2004 , that number was approximately $14 \%$.

Perhaps because of this decline, the United States has lost its position as the leading innovator in a large number of competitive industries such as automotive, steel, ships, machine tools, industrial robots, and the same is occurring in electronics and aeronautics (Bellon and Niosi 1988). If this trend continues, the United States will further lose its scientific and technological leadership in a world where newly energized foreign competitors, such as Japan and the European Community, are investing in the capacity for innovation - the key driver of productivity and economic growth (Bellon and Niosi 1988, p. 9; Wheeler, 2002).

Recent statistics from the 2006 Programme for International Student Assessment (PISA) comparison show that, U.S. students ranked 21 st out of 30 in science literacy among students from developed countries and 25th out of 30 in math literacy (USDOE 2009). The 2009 National Assessment of Education Progress (NAEP) comparison displays that, 4th graders showed no sign of progress for the first time in many years, and 8th graders tailed only modest evidence of progress (USDOE 2009).

To address these negative trends, President Obama has launched an "Educate to Innovate" campaign in 2009 to improve the participation and performance of America's students in STEM subjects. The campaign includes efforts not only from the federal government but also from leading companies, foundations, non-profit organizations, and science and engineering societies to work with young people across America to enter and excel in STEM (The Whitehouse Office of the Press Secretary 2009).

\section{LITERATURE REVIEW ON STEM MODELING}

Associated with attempts to incentivize STEM learning, there have been other modeling efforts to predict how policy decisions might change the demographics and lead to economic opportunity. For example, many states and organizations have STEM related institutes dedicated to supporting education policy. There is the Journal of STEM Education: Innovations and Research and recent articles in other journals describe the job market for STEM graduates (Churbin et al. 2008) and activities to motivate kids to select STEM fields (Brophy et al. 2008).

Here in Ohio, there is the Battelle Center for Science and Education Policy, which is contributing to STEM related modeling focusing on system dynamics, i.e., large scale or "macro" models of the forces governing demographics and economy. Their relatively data-rich and complicated analysis based on system dynamics modeling has been developed collaboratively with partners that include researchers at the Ohio State University Center For Resilience and Raytheon Corporation. The work here is an attempt to 


\section{Allen and Davis}

contribute to this growing body of modeling literature through the study of a relatively simple model that focuses on issues related to peer influence.

\section{A SOCIAL IMPACT THEORY MODEL OF PEER INFLUENCE}

In this section, the core model describing how individuals are influenced by others is described. The model that we pursue is a two-period extension of the single period model, social impact theory model in Nettle (1999). The model was originally proposed as a way to predict the evolution of language. We choose the Nettle (1999) model somewhat arbitrarily because of its relative simplicity and because it permitted exploration of the combined effects of the environment and peer pressures.

The general features of social impact theory models are:

1. Variants - Individuals are influenced to join different variants by the members already associated with that variant. All variants pressure the individuals and the one exerting the highest pressure wins as originally proposed by Latané (1981).

2. Impacts - The impacts or pressures exerted by variants relate to the status and immediacy of the individuals and their number. Generally, larger populations exert more pressure but the pressure is not linearly proportional to size (Latané 1981).

3. Environmental biases - Environmental biases have multiplicative effects on the pressures by the different variants (Nettle 1999).

Much of the theory and numerical studies were codified in the reference book Rockloff and Latané (1996). We adopt notation similar to Troitzsch (1996) and Nettle (1999). In our notation, the pressure on individual $j$ in a variant with $N_{k}$ member is $I_{k}(j)$. The total population has size $N$. Let $Q_{k}$ index the set of individuals currently in variant $k . T_{k, l}$ is the time dependent bias from environmental actors (in our cases teachers) toward variant $k$ in period $l . M_{k}$ is the time independent bias toward variant $k$ (in our case assumed to relate to the job market or other relatively constant external pressures). The status and location of each individual in the peer society are $S_{i}$ and $d_{i}$ respectively. We often visualize the location as a physical place such as the desk in a class room but the mathematics could equally refer to a location in relation to norms in a psychological or philosophical space or a social networking theory space.

Nettle (1999) did not explicitly consider time changing environmental biases. Therefore, the following impact model is a slight extension of Nettle's models:

$$
I_{k}(j)=T_{k_{i} l} M_{k}\left(N_{k}\right)^{a-1} \sum_{\mathrm{i} \in Q_{k, i} i \neq j} \frac{s_{i}}{\left(d_{i}-d_{j}\right)^{2}} \quad \text { for } k=1,2 \text { and } l=1,2
$$

where $a$ is an exponent that we refer to as the "persuasiveness constant" and which (according to Nettle, 1999) typically ranges between 0.5 (moderate peer pressure) to 1 (strong pressure for conformance to group norms). Also, $N_{k}$ is the number of agents of variant $k$. With two variants (STEM and non-STEM) we have $N_{1}+N_{2}=N$ where $N$ is the total cohort size. In our simulations, we generated the $S_{i}$ for $i=$ $1, \ldots, N$ (the status of individual $i$ ) independent identically distributed $\mathrm{U}[0,100]$ following the assumptions in Nowak, Szamrej, and Latané (1990). Visually, in our modeling we use blue for STEM and green for non-STEM.

In equation (1), the acquisition bias is the product of the bias from the educators in period $l$ toward variant $k, T_{k, l}$ and the acquisition bias from the external environment including parental influences and the job market, $M_{k}$. Nettle (1999) employed a similar product of biases assumption but without the potential for time dependence.

\section{THE PROPOSED TWO-PERIOD SIMULATION MODEL}

In this section, the full two-period model which includes four total rounds of peer influence described by equation (1) is described. The full model is intended to describe secondary or high school related student decision-making. Therefore, it covers a four year period. The first period involves the biasing factor, $T_{1,1}$. 


\section{Allen and Davis}

The second period is influenced by the biasing factor, $T_{2,1}$. Clearly, many teachers are involved in each period so that referring to the period-specific bias as Teacher 1 or Teacher 2 is a simplification. Yet, these period-specific biases might be thought of as deriving from key STEM-oriented teachers, Teacher 1 and Teacher 2 corresponding to the periods. Figure 1 shows the process overview and the inputs (xs) varied and the response $(y)$ measured in our numerical study.

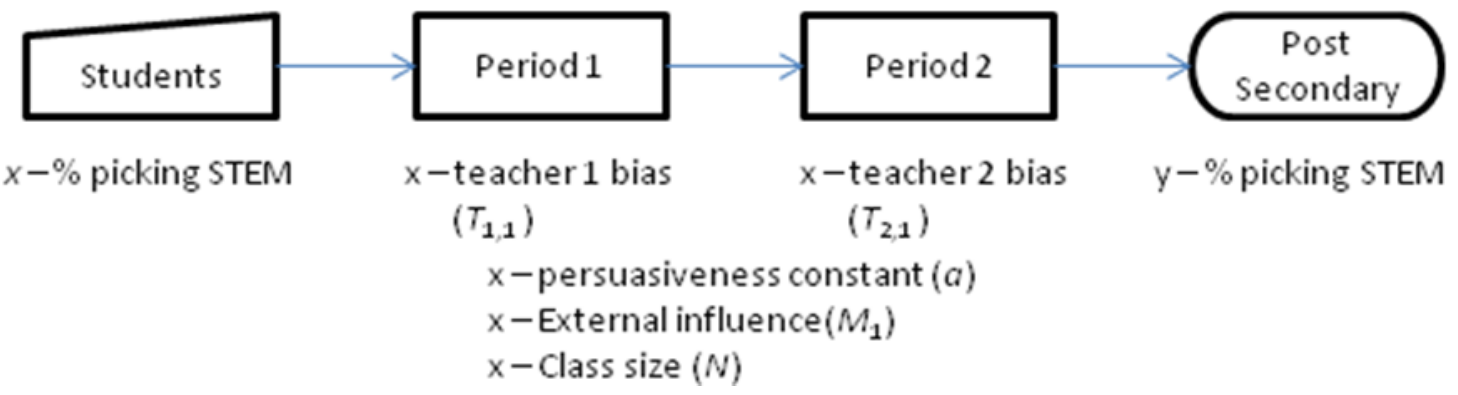

Figure 1: STEM model flow chart, where the " $x \mathrm{~s}$ " are varied in the study and the " $y \mathrm{~s}$ " are measured

\subsection{The Two Period Model}

In all our simulations, we assume that $40 \%$ of the initial students start out with variant 1 (STEM) based on the results of the Raytheon (2009) survey of middle students in the U.S. and their favorite subject out of five choices being either science or mathematics. Further, we assume distances are given by a rectangular shaped class room. Also, for simplicity and with minimal loss of generality, we assume that $T_{2,1}=$ $T_{2,2}=M_{2}=1$. In this way, bias away from STEM corresponds to values of $T_{1,1}, T_{2,1}$, and $M_{1}$ less than 1.0. Similarly, bias toward STEM corresponds to values of $T_{1,1}, T_{2,1}$, and $M_{1}$ greater than 1.0.

The model also includes the possibility that students might be divided by their STEM or non-STEM variant (segregated) or randomly assigned in both periods. Our segregation took the form of simply placing STEM students on one end of the class (with reference to physical locations). However, the mathematics is general enough, perhaps, to relate to the concept of special sections of STEM students or fully integrated instruction.

\subsection{Implementation in NetLogo}

To implement the model and aid in visualization, we used the cross-platform multi-agent programmable modeling environment, Netlogo. It is a programmable modeling environment for simulating natural and social phenomena and is particularly well suited for modeling complex systems developing over time (Wilensky 1999). Instructions can be given to hundreds of agents, all operating independently, in order to explore the connection between the micro-level behavior of individuals and the macro-level patterns that emerge from the interactions of many individuals. The flowchart in Figure 2 shows the process and sequence of execution taking place in our NetLogo model.

Our simulation space is partitioned into quadrants of which the lower sections represent two classrooms, as shown in Figure 3. Simulated student instruction and peer influencing takes place there. The upper sections of the quadrant shows the transition of students into the job markets for both STEM and non-STEM areas. The agent representing the STEM job market, in the shape of a computer in this model, form links with the students emerging as STEM oriented individuals while the agent representing the nonSTEM market, shaped as a person holding a briefcase, captures students geared towards a career outside of STEM.

In the model, teachers are agents that are responsible for influencing student agents to follow a STEM career path at each of levels 1 and 2 represented by the left and right quadrants respectively in Figure 2. The STEM and Non-STEM job markets are agents created with the variable strength, having an influen- 


\section{Allen and Davis}

cing impact on students to join either the STEM or Non-STEM job markets. All of these initializing conditions and parameters are executed when the model's "setup" button is clicked.

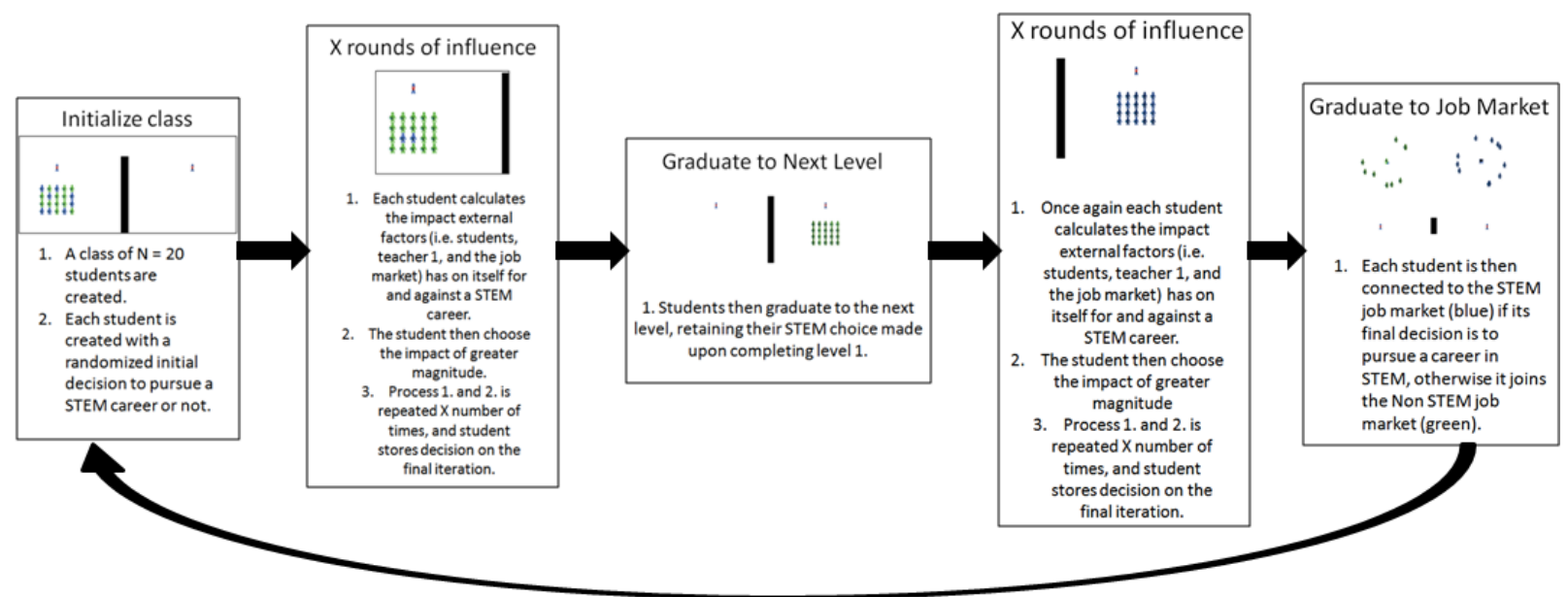

Figure 2: STEM model flow chart

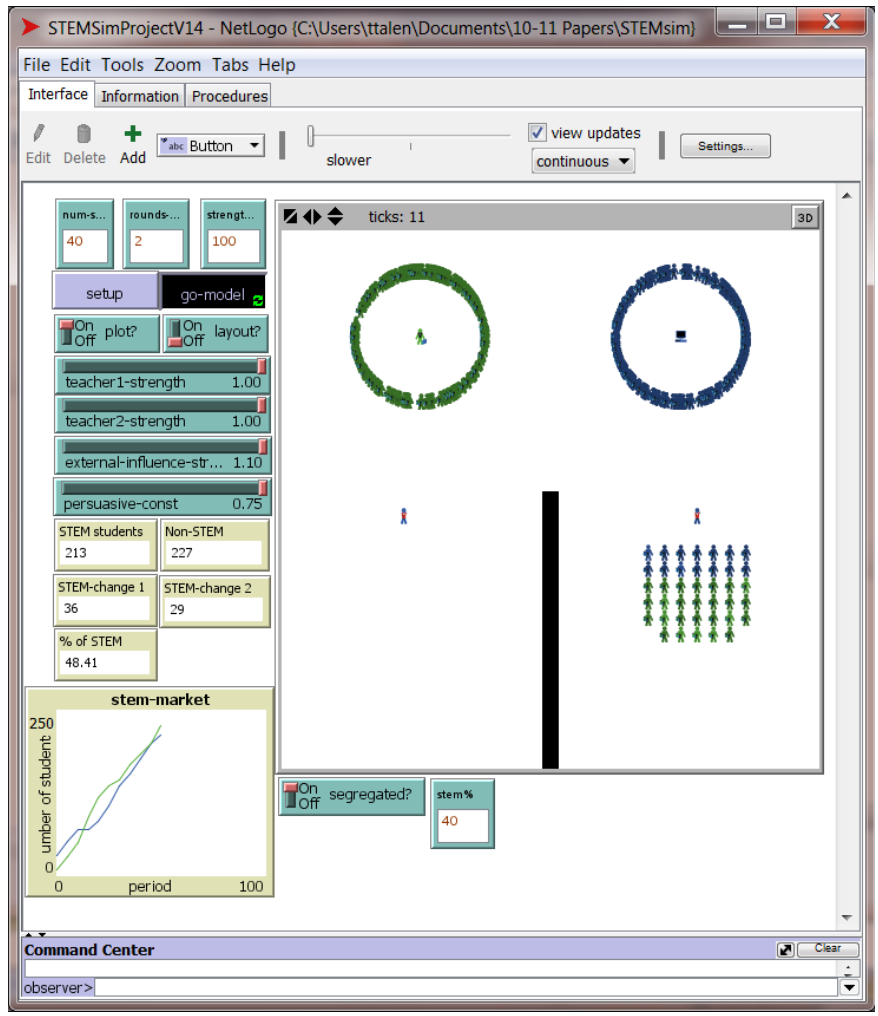

Figure 3: STEM-Sim model in process

\section{SIMULATION EXPERIMENTS}

In this section, we describe two computational experiments conducted using the model described in previous sections. The model is available upon request from the authors and requires minimal installation at no cost. The first experiment was a $2^{6-1}$ regular fractional factorial. Conducting this experiment provided 


\section{Allen and Davis}

the only real verification and validation of the developed model. The code was verified in the sense that the analysis results were considered to be intuitively believable and validated to the extent that many of the outputs predicted were in the rough ball park of the 14\% STEM major selections observed in Chen and Weko (2009).

Table 1 shows the factors selected and ranges for the fractional factorial experiment. The persuasiveness range was roughly that considered by Nettle (1999) except the high end was only 0.75 rather than 1.0. This seemed more relevant to the relatively low peer pressure associated with major selection compared with the high pressure assumed relevant for language conformance. Also, the ranges are intended to include teachers that bias students away from STEM selections, e.g., charismatic English teachers or uncharismatic science teachers. The job market bias range straddled the non-influential 1.0 setting because, in our subjective experience, the environment and job market ranges do vary from cohort-to-cohort and place-to-place. Somewhat arbitrarily, we consider cohorts ranging from 20 to 40 only corresponding at least roughly to class sizes that we ourselves have experienced.

Table 1: Factors and levels for experimental design

\begin{tabular}{lccc}
\hline Factor & Parameter & Low & High \\
\hline A. Persuasiveness constant & $a$ & 0.50 & 0.75 \\
B. Bias established by teacher 1 & $T_{1,1}$ & 0.75 & 1.00 \\
C. Bias established by teacher 2 & $T_{1,2}$ & 0.75 & 1.00 \\
D. Bias established by the job market & $M_{1}$ & 0.90 & 1.10 \\
E. Cohort size & $N$ & 20 & 40 \\
F. Whether individuals cluster by variant & Integration & Random assignment & Segregated \\
\hline
\end{tabular}

The inputs and outputs for the $2^{6-1}$ regular fractional factorial experiment are shown in Table 2. Each STEM percentage was estimated by the total number of STEM and non-STEM students after 50 replications of initialization and four rounds of influence. Specifically, in each replicate, there was an initialization of the students based on the integration setting and student Status values, $S_{i}$. The integration setting was determined from the experimental design in Table 2 . Then, the four rounds were simulated using equation (1) for each student.

Table 3 shows the results from the fitting of a linear model including second order interactions to the response data. The analysis of the linear model can help us to interpret our agent-based model and to determine which factors have effects that are large enough that they are truly present in the agent-based model and not a byproduct of estimation errors caused by the randomness built into the simulations. Overall, the R-squared adjusted of this model was $93.9 \%$ which indicates that the simple second order polynomial captures the majority of the information contained in the agent-based model over the range of factors studied.

Further, the normal probability plot of effects in Figure 4 suggests that few (if any) important interaction effects are left-out of the second order model. The dots near the line in Figure 4 signify estimated effects that are not significant and likely are nonzero only because of the randomness built into the simulations. The models indicate that all of main effects have significant effects with the cohort size having a somewhat small effect over the range considered. Also, the persuasiveness $(a)$ has significant interactions with Teacher 2, the external influence, and the integration factor. Both teacher factors interact significantly with the integration factor as does the cohort size. 
Table 2: Experimental design inputs and output (\% STEM estimated using 50 replicates)

\begin{tabular}{cccccccc}
\hline Run & Persuasiveness & Teacher 1 & Teacher 2 & Environment & Size & Integration & \% STEM \\
\hline $\mathbf{1}$ & 0.5 & 0.75 & 0.75 & 0.9 & 20 & Random & 7.00 \\
$\mathbf{2}$ & 0.75 & 0.75 & 0.75 & 0.9 & 20 & Segregated & 5.10 \\
$\mathbf{3}$ & 0.5 & 1 & 0.75 & 0.9 & 20 & Segregated & 17.20 \\
$\mathbf{4}$ & 0.75 & 1 & 0.75 & 0.9 & 20 & Random & 21.12 \\
$\mathbf{5}$ & 0.5 & 0.75 & 1 & 0.9 & 20 & Segregated & 19.70 \\
$\mathbf{6}$ & 0.75 & 0.75 & 1 & 0.9 & 20 & Random & 13.50 \\
$\mathbf{7}$ & 0.5 & 1 & 1 & 0.9 & 20 & Random & 21.00 \\
$\mathbf{8}$ & 0.75 & 1 & 1 & 0.9 & 20 & Segregated & 23.16 \\
$\mathbf{9}$ & 0.5 & 0.75 & 0.75 & 1.1 & 20 & Segregated & 27.60 \\
$\mathbf{1 0}$ & 0.75 & 0.75 & 0.75 & 1.1 & 20 & Random & 20.80 \\
$\mathbf{1 1}$ & 0.5 & 1 & 0.75 & 1.1 & 20 & Random & 38.90 \\
\hline $\mathbf{1 2}$ & 0.75 & 1 & 0.75 & 1.1 & 20 & Segregated & 30.00 \\
$\mathbf{1 3}$ & 0.5 & 0.75 & 1 & 1.1 & 20 & Random & 28.06 \\
$\mathbf{1 4}$ & 0.75 & 0.75 & 1 & 1.1 & 20 & Segregated & 26.60 \\
$\mathbf{1 5}$ & 0.5 & 1 & 1 & 1.1 & 20 & Segregated & 57.60 \\
\hline $\mathbf{1 6}$ & 0.75 & 1 & 1 & 1.1 & 20 & Random & 42.50 \\
$\mathbf{1 7}$ & 0.5 & 0.75 & 0.75 & 0.9 & 40 & Segregated & 15.65 \\
\hline $\mathbf{1 8}$ & 0.75 & 0.75 & 0.75 & 0.9 & 40 & Random & 3.45 \\
$\mathbf{1 9}$ & 0.5 & 1 & 0.75 & 0.9 & 40 & Random & 7.85 \\
\hline $\mathbf{2 0}$ & 0.75 & 1 & 0.75 & 0.9 & 40 & Segregated & 17.45 \\
$\mathbf{2 1}$ & 0.5 & 0.75 & 1 & 0.9 & 40 & Random & 4.50 \\
\hline $\mathbf{2 2}$ & 0.75 & 0.75 & 1 & 0.9 & 40 & Segregated & 15.25 \\
$\mathbf{2 3}$ & 0.5 & 1 & 1 & 0.9 & 40 & Segregated & 32.00 \\
$\mathbf{2 4}$ & 0.75 & 1 & 1 & 0.9 & 40 & Random & 15.55 \\
$\mathbf{2 5}$ & 0.5 & 0.75 & 0.75 & 1.1 & 40 & Random & 12.40 \\
$\mathbf{2 6}$ & 0.75 & 0.75 & 0.75 & 1.1 & 40 & Segregated & 19.15 \\
$\mathbf{2 7}$ & 0.5 & 1 & 0.75 & 1.1 & 40 & Segregated & 38.00 \\
\hline $\mathbf{2 8}$ & 0.75 & 1 & 0.75 & 1.1 & 40 & Random & 31.95 \\
$\mathbf{2 9}$ & 0.5 & 0.75 & 1 & 1.1 & 40 & Segregated & 40.70 \\
\hline $\mathbf{3 0}$ & 0.75 & 0.75 & 1 & 1.1 & 40 & Random & 10.15 \\
$\mathbf{3 1}$ & 0.5 & 1 & 1 & 1.1 & 40 & Random & 46.85 \\
$\mathbf{3 2}$ & 0.75 & 1 & 1 & 1.1 & 40 & Segregated & 37.85 \\
\hline & & & & & & & \\
\hline
\end{tabular}

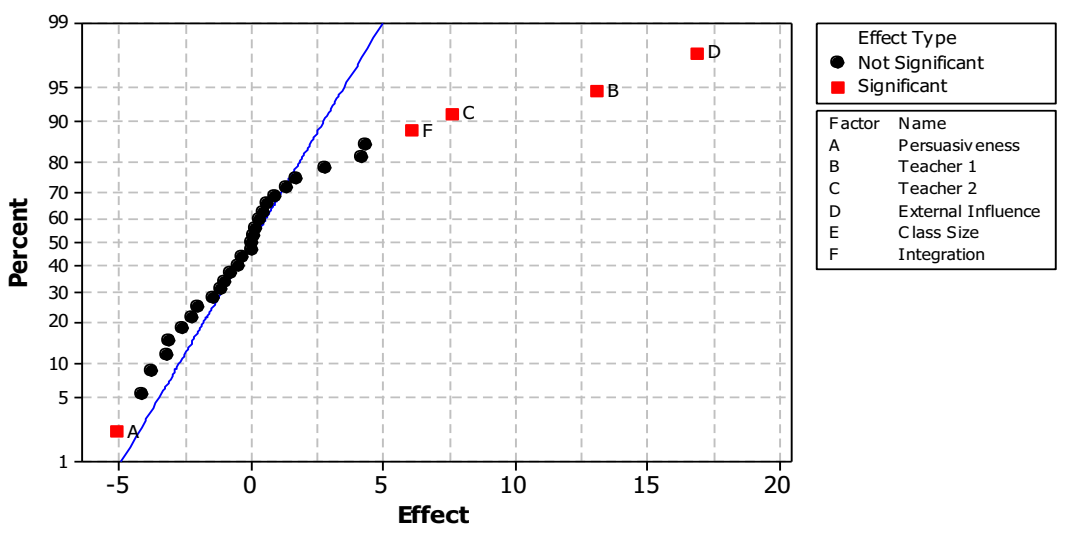

Figure 4: Main effects plot from the simulation experiment 


\section{Allen and Davis}

Table 3: ANOVA table for the model including interactions up to order 2

\begin{tabular}{cccccc}
\hline Term & Effect & Coef & SE Coef & T & P \\
\hline Constant & & 23.39 & 0.59 & 39.89 & 0.00 \\
\hline Persuasiveness & -5.09 & -2.55 & 0.59 & -4.34 & 0.00 \\
Teacher 1 & 13.09 & 6.54 & 0.59 & 11.16 & 0.00 \\
\hline Teacher 2 & 7.58 & 3.79 & 0.59 & 6.47 & 0.00 \\
\hline External Influence & 16.85 & 8.43 & 0.59 & 14.37 & 0.00 \\
\hline Cohort Size & -3.19 & -1.60 & 0.59 & -2.72 & 0.02 \\
\hline Integration & 6.09 & 3.05 & 0.59 & 5.19 & 0.00 \\
\hline Persuasiveness*Teacher 1 & 0.11 & 0.06 & 0.59 & 0.10 & 0.93 \\
\hline Persuasiveness*Teacher 2 & -3.14 & -1.57 & 0.59 & -2.68 & 0.02 \\
\hline Persuasiveness*External Influence & -3.80 & -1.90 & 0.59 & -3.24 & 0.01 \\
\hline Persuasiveness*Cohort Size & -0.80 & -0.40 & 0.59 & -0.69 & 0.51 \\
\hline Persuasiveness*Integration & -4.15 & -2.07 & 0.59 & -3.54 & 0.01 \\
\hline Teacher 1*Teacher 2 & 1.67 & 0.84 & 0.59 & 1.42 & 0.19 \\
\hline Teacher 1*External Influence & 4.19 & 2.09 & 0.59 & 3.57 & 0.01 \\
\hline Teacher 1*Cohort Size & 0.20 & 0.10 & 0.59 & 0.17 & 0.87 \\
\hline Teacher 1*Integration & -2.65 & -1.32 & 0.59 & -2.26 & 0.05 \\
\hline Teacher 2*External Influence & 1.35 & 0.68 & 0.59 & 1.15 & 0.28 \\
\hline Teacher 2*Cohort Size & -0.47 & -0.23 & 0.59 & -0.40 & 0.70 \\
Teacher 2*Integration & 2.75 & 1.38 & 0.59 & 2.35 & 0.04 \\
\hline External Influence*Cohort Size & -1.18 & -0.59 & 0.59 & -1.01 & 0.34 \\
\hline External Influence*Integration & -0.35 & -0.18 & 0.59 & -0.30 & 0.77 \\
\hline Cohort Siz**Integration & 4.33 & 2.17 & 0.59 & 3.69 & 0.00 \\
\hline
\end{tabular}

The main effects plot in Figure 5 and the previous significance related information together support the following findings:

1. Reaching students early is important. The effects of biases (Teacher 1$)$ in the initial period (2 years) are greater than biases later in the high school period by $5.5 \%$. This could mean, e.g., that allocating a star STEM-oriented teacher to younger students rather than older by itself could increase the percentage of STEM majors from $14 \%$ to almost $20 \%$. Intuitively, this might be explained as an early drop in the percentage interested in STEM compounds because of the then increased peer effects during the second period.

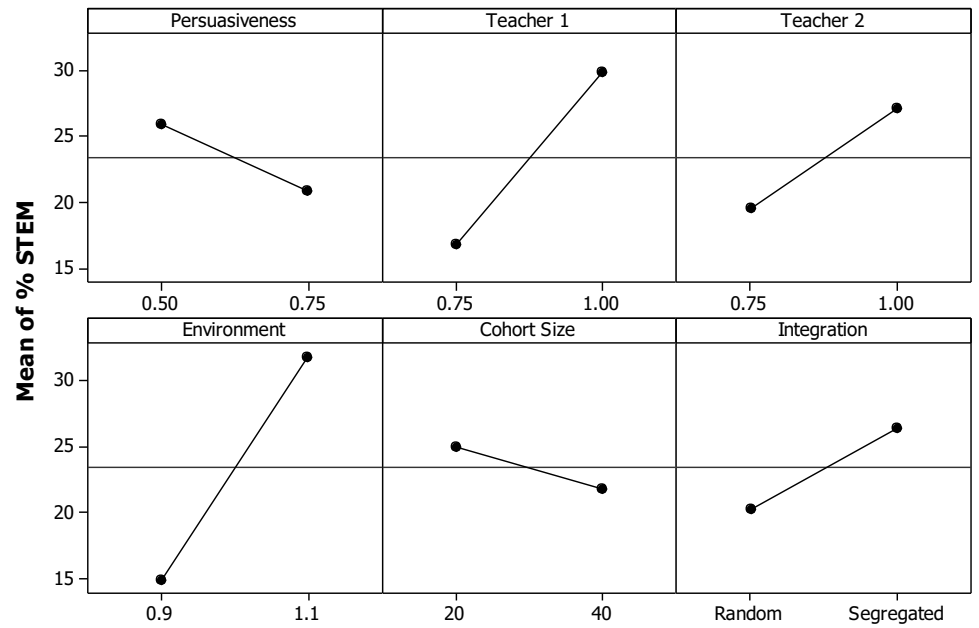

Figure 5: Main effects plot from the simulation experiment 


\section{Allen and Davis}

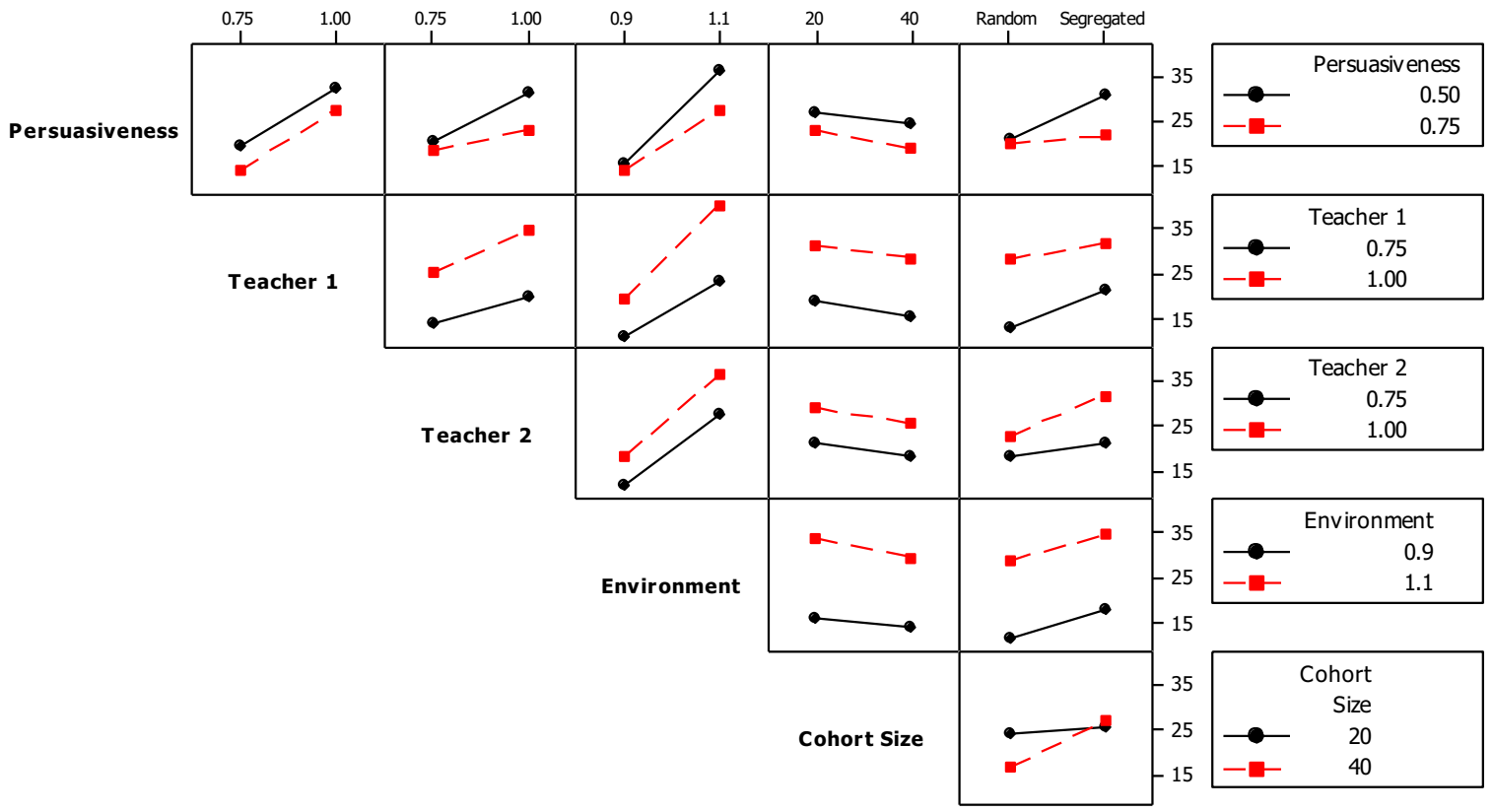

Integration

Figure 6: Interaction plots from the simulation experiment.

2. Segregating the students by STEM preference is important, particularly for large cohorts. Intuitively, students interested in STEM are a minority in the U.S. and protecting that minority helps to preserve it. The model predicts that segregation in large cohorts (size 40) could increase the yield of STEM majors by as much as $10 \%$. It is true, of course, that dividing students into STEM oriented sections or schools could have negative effects on the other students. Not only will the other students be less likely to orient toward STEM pursuits but they may also lose the peer pressure to think critically or even to avoid negative activities such as drugs or crime.

Subjectively, the output STEM\% seems quite sensitive to the overall environmental bias $\left(\mathrm{M}_{1}\right)$ presumably because it exerts constant pressure over both periods. It is perhaps interesting to note that model contains a "tipping point" of the type described by Gladwell (2002). For example, consider what happens if we set $T_{1}=T_{2}=1$, cohort size to 40 , integration to random, and vary the external influence $\left(M_{1}\right)$. Figure 7 shows the outputs from 50 replications of the agent-based model overlaid with a sixth order polynomial and its associated prediction confidence intervals. With a single factor varied only and others held constant and having so many levels, we have great modeling flexibility. We chose a sixth order polynomial because it seemed visually to provide a good fit. The model shows that if the external influence reaches a certain point, the peer pressure effects in the model start working to reinforce STEM pursuits. This results in the further finding:

3. Small external effects could result in a rapid transition toward STEM oriented populations as indicated in Figure 7. For example, if the job market for STEM students in the U.S. population improved or the perceptions changed, we might have a fairly sudden change in the percentages. For example, shifting the bias from 0.8 to 1.2 results in an over $40 \%$ shift in the percent interested in STEM pursuits. Intuitively, this might occur because STEM oriented students might transition from a small minority to the majority and the peer pressure influences might push in the opposite direction. This has presumably occurred throughout Asia in recent years. 


\section{Allen and Davis}

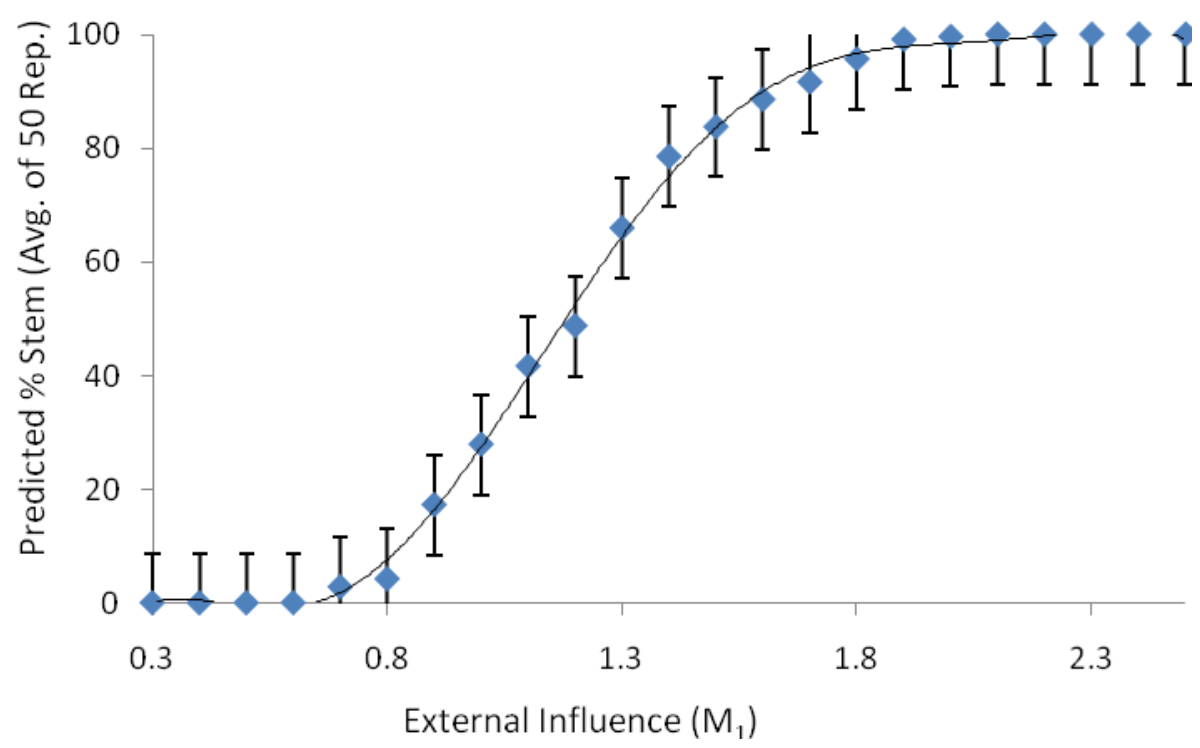

Figure 7: The predicted "tipping point" or transition from non-STEM to STEM as environmental biases change. The model assumes $a=0.5, \mathrm{~T}_{1,1}=\mathrm{T}_{2,1}=1$, cohort size $=40$, and integrated classes.

This last finding offers a potentially simple way to check the validity of the model. One could study other countries or pockets of countries where external biases are different. Are non-STEM students minorities in these cohorts as the model predicts? Are there lessons for educators in the US about how to create the external pressures? If the model is correct, importing STEM oriented labor from abroad to meet job market needs might be contributing greatly to reduced interest in STEM pursuits within the U.S. These imports were not present in our high schools to influence other students.

\section{CONCLUSIONS AND OPPORTUNITIES FOR FURTHER RESEARCH}

This article has proposed and studied an agent-based two period model for investigating the factors that influence student selection of STEM majors in U.S. colleges. The computational experiments on the model have suggested significant benefits related to reaching students early, segregating STEM students, and making changes to the job market. The model predicts that potentially small changes at minimal (if any) cost could more than double the percentages of students selecting STEM majors. For example, shifting earlier the STEM oriented teaching talent to teach sophomores instead of seniors is predicted to increase the STEM major yield by approximately 5.5\%. Also, dividing or "segregating" students by orientation to STEM subjects into separate groups is predicted to increase the STEM yield by over $10 \%$. In addition, the implications of the tipping point associated with the model predictions imply that what might seem like small environmental changes could precipitate a dramatic shift.

The research leaves a number of questions for future study. First, data can be collected about actual cohorts of students and about their environmental conditions. Such data can be used to validate the model and/or identify features that need to be added. Second, a systematic comparison of the proposed modeling approach with alternatives such as system dynamics modeling (e.g., see Sanchez, Wells, and Attridge, 2009). The investigation can evaluate whether the simpler models here capture any elements missed in the more extensive models or vice versa. Hybrid models might be produced if appropriate. Third, more realistic models of the distances and nature of student cohorts might be considered. For example, peer groups might be larger than 40 and the nature of their influence processes might be very different than indicated by the simple square class-room structure considered here. Finally, a list of actual best practices associated with successful high schools can be compiled and studied in relation to model validation and communicating results to educators. 


\section{Allen and Davis}

\section{ACKNOWLEDGMENTS}

We thank Robert Gustafson, Clark Mount-Campbell, and Kathryn Sullivan for valuable information.

\section{REFERENCES}

Allen, T. T. 2010. Introduction to discrete event simulation and agent-based modeling: voting systems, health care, military, and manufacturing. London: Springer Verlag.

Appelbaum, E., and R. Batt. 1994. The new American workplace. Ithaca, NY: ILR Press.

Baker, S., and R. Petty. 1994. Majority and minority influence: source-position imbalance as a determinant of message scrutiny. Journal of Personality and Social Psychology 67:5-19.

Bellon, B., and J. Niosi. 1988. The decline of the American economy. Montreal, Quebec: Black Rose Books.

Brophy, S., S. Klein, and M. Portsmore, and C. Rogers. 2008. Advancing engineering education in P-12 classrooms. Journal of Engineering Education 97: 369-387.

Brophy, J. 1986. Teacher Influences on student achievement. American Psychologist: 41, 1069-1077.

Carley, K. 2006. BioDefense through city level multi-agent modeling of bio and chemical threats. Arizona Spring Biosurveillance Workshop, Tucson, Arizona.

Chen, X., and T. Weko. 2009. Students who study science, technology, engineering, and mathematics (STEM) in postsecondary education. Institute of Education Sciences, National Center For Education Statistics, U.S. Department of Education NCES 2009-161.

Conte R, B. Edmonds, S. Moss, and K.R. Sawyer. 2001. Sociology and social theory in agent based simulation: a symposium. Computational and Mathematical Organization Theory 7: 183-205.

Churbin, D., K. Donaldson, B. Olds, and L. Fleming. 2008. Educating generation net - can U.S. engineering woo and win the competition for talent? Journal of Engineering Education 97: 245-257.

Fang, C., S. O. Kimbrough, A. Valluri, and Z. Zheng. 2002. On adaptive emergence of trust behavior in the game of stag hunt. Group Decision and Negotiation 11: 449-467.

Gilbert G. N., and J. E. Doran (Eds.) Social science microsimulation. New York, NY: Springer-Verlag.

Gilbert G. N, and K. G. Troitzsch. 2005. Simulation for the social scientist. New York, NY: McGrawHill.

Gladwell, M. 2002. The tipping point: how little things can make a big difference. New York: Black Bay Books.

Huang C. Y., C. T. Sun, J. L. Hsieh, and H. Lin. 2004. Simulating SARS: small-world epidemiological modeling and public health policy assessments. Journal of Artificial Societies and Social Simulation 7: 100-131.

Keller, J. 1983. Motivational design of instruction. In Instructional design theories and models: An overview of their current status, ed. C. M. Reigeluth, 383-434. Hillsdale, NJ: Erlbaum.

Latané B. 1981. The psychology of social impact. American Psychologist 36:343-356.

Latané, B. 1996. Strength from weakness: the fate of opinion minorities in spatially distributed groups. In Understanding Group Behavior, ed. E. Witte and J.H. Davis. Mahwah, NJ: Lawrence Erlbaum Associates, Inc.

Macal, C. M., and M.J. North. 2006. Tutorial on agent-based modeling and simulation part 2; how to model with agents. In Proceedings of the 2006 Winter Simulation Conference, ed. L. F. Perrone, F. P. Wieland, J. Liu, B. G. Lawson, D. M. Nicol, and R. M. Fujimoto, 73-83. Piscataway, New Jersey: Institute of Electrical and Electronics Engineers, Inc.

Macal, C.M., and M. J. North. 2007. Agent-based modeling and simulation: desktop ABMS. In Proceedings of the 2007 Winter Simulation Conference. ed. S. G. Henderson, B. Biller, M.-H. Hsieh, J. Shortle, J. D. Tew, and R. R. Barton, 95-106. Piscataway, New Jersey: Institute of Electrical and Electronics Engineers, Inc.

Nettle, D. 1999. Using Social Impact Theory to simulate language change. Lingua 108:95-117. 


\section{Allen and Davis}

Nowak, A., J. Szamrej, and B. Latané . 1990. From private attitude to public opinion: a dynamic theory of social impact. Psychological Review 97:362-376.

Raytheon $2009 . \quad$ Available via <http://www.raytheon.com/responsibility/stem/model/index.html> [accessed September 14, 2010].

Rockloff, M. J., and B. Latané. 1996. Simulating the social context of human choice. In Social Science Microsimulation, ed. K. G. Troitzsch, U. Mueller, G.N. Gilbert, and J.E. Doran 360-388. London, U.K.: Springer Verlag.

Sanchez, H. A., B. Wells, and J. M. Attridge. 2009. Using system dynamics to model student interest in science technology, engineering, and mathematics. In Proceedings of The 27th International Conference of the System Dynamics Society, Albuquerque, New Mexico, USA.

Skinner E. A., and M. J. Belmont. 1993. Motivation in the classroom: reciprocal effects of teacher behavior and student engagement across the school year. Journal of Education Psychology 85:71 - 581.

TAP 2008. Tapping America's potential: the education for innovation initiative. gaining momentum, losing ground. Washington, D.C.: Business Roundtable.

The Whitehouse Office of the Press Secretary. 2009. Educate to Innovate. Available via <http://www. whitehouse.gov/issues/education/educate-innovate> [accessed September 9, 2010].

USDOE 2009. Stats in brief: students who study science, technology, engineering, and mathematics (STEM) in postsecondary education. U.S. Department of Education. Available via <http://nces.ed.gov/pubs2009/2009161.pdf> [accessed September 9, 2010].

Weiner, B. 1986. An attribution theory of motivation and emotion. New York: Springer-Verlag.

Wheeler, H. N. 2002. Future of the American labor movement. Cambridge, UK: Cambridge University Press.

Wilensky, U. 1999. NetLogo. Center for Connected Learning and Computer-Based Modeling, Northwestern University, Evanston, IL. Available via <http://ccl . northwestern. edu/netlogo/> [accessed September 9, 2010].

\section{AUTHOR BIOGRAPHIES}

THEODORE T. ALLEN is an Associate Professor of Integrated Systems Engineering at The Ohio State University. Dr. Allen's research is devoted to the interaction between statistical models, data collection, optimization, and human-computer interaction. He has co-authored or authored over forty peer reviewed publications and two textbooks including a recent textbook on simulation and agent-based modeling intended to help bridge between the classroom and the Winter Simulation Conference. His research on simulating election systems has gained international attention and is featured in his simulation textbook. He is a fellow of the American Society For Quality. His email address is <allen.515@osu. edu>.

NIXON DAVIS received his M.S. degree from the The Ohio State University in Integrated Systems Engineering in 2010. Currently, he works as a production and quality engineer at a major US manufacturer. His email address is <davis.3156ebuckeyemail.osu.edu>. 